\title{
New filtering operation for open-angle glaucoma using a rolled corneo-scleral flap
}

\author{
ZVI AVINER* \\ Eye Department, Queen Elizabeth Central Hospital, Blantyre, Malawi
}

A crucial step to avoid failure of a filtering operation is to prevent adhesions of the conjunctival flap to the sclera in the early postoperative period (Friedenwald, 1950).

The aim of this communication is to describe a way by which the conjunctival flap is supported by a rolled corneo-scleral flap, so that a high, limited bleb is created immediately after the operation.

\section{Method}

The conjunctival flap is prepared and reflected over the cornea by the method described by Scheie (1958) and the limbal area is exposed. With the blade of a scalpel, held perpendicularly to the limbal plane, a cut $3 \mathrm{~mm}$. long is made in the limbal tissue (Fig. I $a, b$ ) concentric to the limbus more than half the depth of the sclera. At either end, two cuts $\mathrm{I} \cdot 5 \mathrm{~mm}$. long are made perpendicular to the previous one to the same depth. A rectangular trap-door of corneo-scleral tissue, its base being attached to the scleral side, is dissected by a scalpel (Fig. Ic). The anterior chamber is still intact. Bleeding points are gently controlled by a cautery.

A double 8/o virgin silk suture is passed through the base of the trap-door from the anterior face (Fig. I $d$ ) and then brought backwards through the very margin of the flap. By tying the two ends of the sutures the trap-door is rolled into a cylinder (Fig. I $e$ ).

The anterior chamber is now opened with a scalpel at the very end of the scleral groove (Fig. I $f$ ). The posterior lip of the wound is firmly grasped with fine-toothed forceps and slightly pulled up. A second cut is made with the scalpel parallel to the first one, and slightly backwards, so that a narrow strip of limbal tissue is being held up by the forceps. With a few strokes of the scalpel at each side, the strip is completely separated.

Through the narrow rectangular opening a peripheral iridectomy is done. The conjunctival flap is turned backwards over the rolled corneo-scleral flap and tied at the original cut, $8 \mathrm{~mm}$. above the limbus, by a continuous $8 / 0$ suture (Fig. $1 \mathrm{~g}$ ). A fine bleb is now seen, the posterior margin of which is elevated by the rolled flap. Restoration of the anterior chamber is not necessary. A drop of atropine sulphate I per cent. and a drop of steroid are instilled in the conjunctival cul-de-sac and the eye is closed with a pad. Postoperatively the pad is changed daily and atropine I per cent. drops and local steroid drops are applied.

\section{Results}

During the period August, I97 I, to February, 1972, the operation was performed on thirty eyes of African patients suffering from chronic open-angle glaucoma. Three of them had previously had another filtering procedure which had failed. The early postoperative period was uneventful and no case of persistent shallow chamber or choroidal detachment has been seen. All were discharged from the hospital 2 weeks after operation 

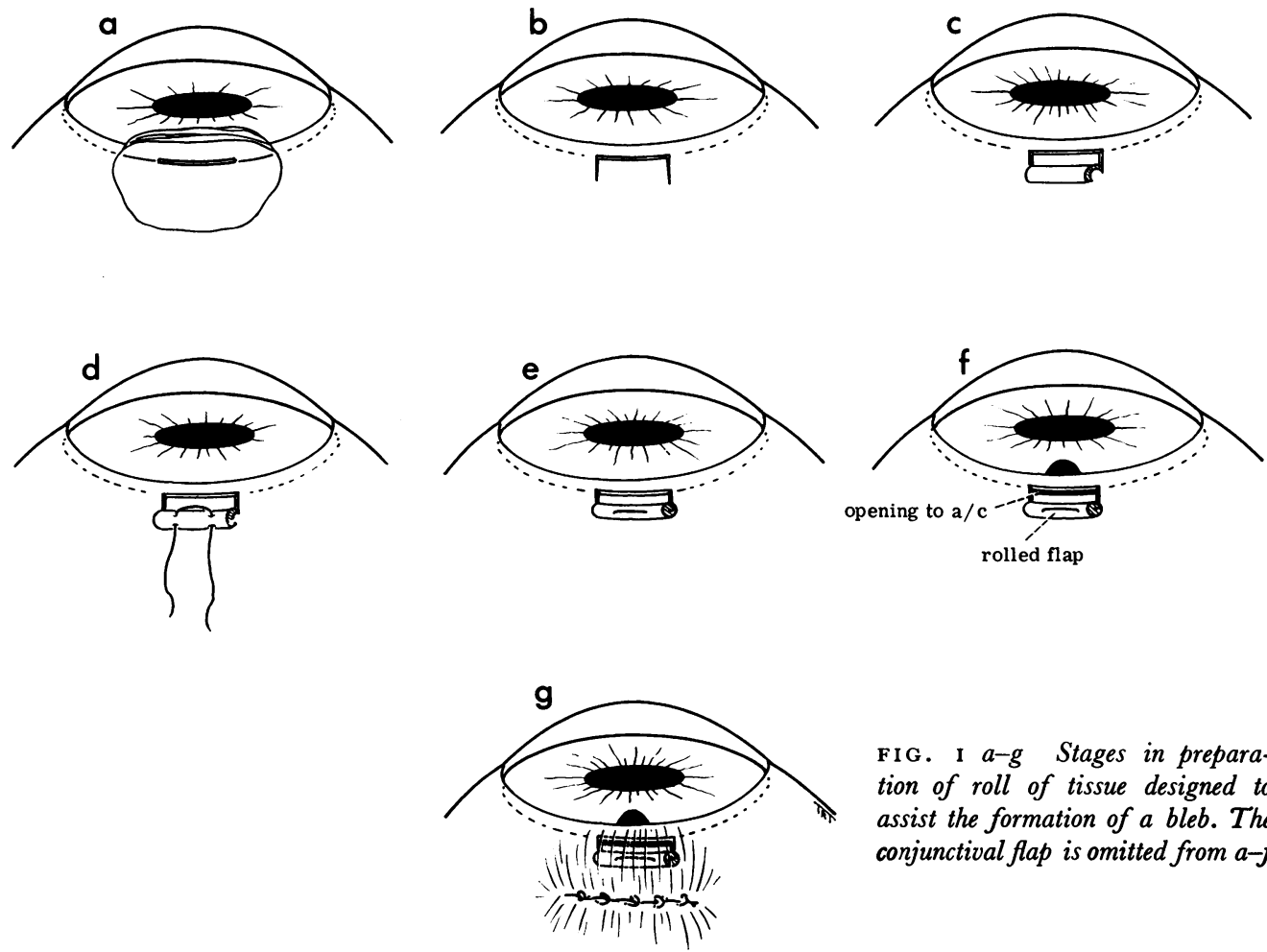

FIG. I $a-g$ Stages in preparation of roll of tissue designed to assist the formation of a bleb. The conjunctival flap is omitted from $a-f$

with a good functional bleb slightly raised above the scleral plane but never diffuse. In the follow-up period of 4 to 9 months, the blebs were still functioning in all of the patients. No case of iritis, scleritis, or cataract was seen.

\section{Discussion}

The success of a filtering operation depends very much upon the prevention of adhesions between the conjunctival flap and the sclera. The factors predisposing to postoperative scarring are operative trauma, haemorrhage, inflammation, and racial characteristics (Friedenwald, 1950). Negroes are particularly prone to develop scar-tissue at the site of the operation, so that a very low rate of success with filtering operations has been reported, not greater than 30 per cent. according to Berson, Zauberman, Landau, and Blumenthal (r 969 ). Better results can be obtained by the excision of Tenon's capsule (Ben Sira and Ticho, 1969). In our department, during the period from January, I97 I, to September, 1971, 23 eyes of 23 African patients were operated on by the methods of Elliot (1909), Lagrange (1937), and Scheie, (1958), Tenon's capsule being meticulously excised in all of them, but 2 months after the operation, in twelve eyes, the bleb was closed and the intraocular pressure was high. The good results obtained with the new method described above are thus the more remarkable.

The failure of the filtering blebs usually takes place 2 to 4 weeks after operation (Scheie, 1958; Ben Sira and Ticho, 1969). It seems, therefore, that the separation of the conjunctival "roof" of the bleb from its scleral "floor" should exist from the end of the operation. The infiltration of fluid under the conjunctiva does not usually help much, in my experience, because the fluid is easily spread under the wide conjunctival flap. For the 
same reason the aqueous humour cannot support the bleb, and the reduced rate of aqueous production postoperatively (Goldmann, I95I) increases this handicap.

By the new method, the conjunctiva is kept high above the sclera immediately after the operation ( $a$ ) by the scleral flap, which acts like a pillow, and $(b)$ by digging the "floor" of the bleb deep into the sclera (Fig. 2). When the conjunctiva is stretched from its insertion at the anterior margin of the limbal area backwards to lie over the raised scleral flap, it converts the normal corneo-scleral sulcus to a bleb space. The aqueous humour which pours out through the new orifice cannot diffuse freely under the conjunctiva; its path is limited by the flap posteriorly and by the walls of the groove laterally and medially. The aqueous humour accumulates under the conjunctiva at the groove and separates it from the sclera. The scleral flap thus provides the resistance to the flow of aqueous which is needed to prevent the anterior chamber becoming too shallow in the early postoperative period.

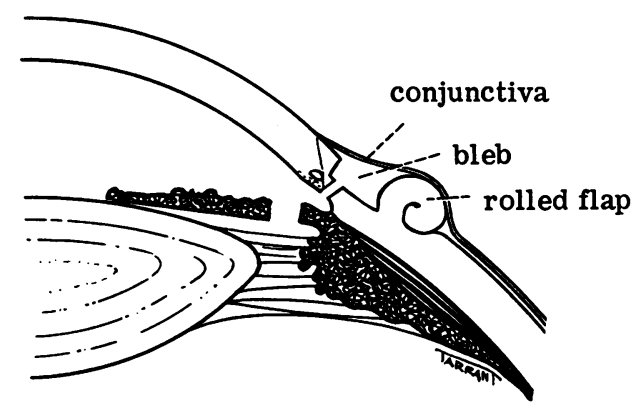

FIG. 2 Cross-section, showing conjunctival flap resting on roll of tissue

\section{Summary}

A new type of filtering operation is described. A rectangular trap-door of corneo-scleral tissue is dissected, with its base backwards, and is rolled up into a cylinder by a doublearmed 8/o suture. The anterior chamber is opened at the anterior part of the groove. The conjunctival flap is spread over the corneo-scleral sulcus and rests on the rolled corneo-scleral flap. The conjunctiva thus stays high above the irritated sclera, and adhesions are avoided in the critical early postoperative period. Good results were obtained in thirty eyes of African patients.

\section{References}

BEN SIRA, I., and TICHO, U. (1969) Amer. F. Ophthal., 68, 336

Berson, D., ZAUberman, H., LANDAU, L., and blumenthal, M. (1969) Ibid., 67, 395

ELLIOTT, H. R. (1909) Ophthalmoscope, 7, 804

FRIEDENWALd, J. s. (1950) Amer. F. Ophthal., 33, I523

GOLDMANN, H. (195I) Ophthalmologica (Basel), 121, 94

Lagrange, H. (1937) Brit. F. Ophthal., 21, 477

SCHEIE, H. G. (1958) Trans. Canad. ophthal. Soc., ro, 31, 129 